\title{
IMPORTÂNCIA DE CARACTERES NA DISSIMILARIDADE DE PROGÊNIES DE BATATA EM GERAÇÕES INICIAIS DE SELEÇÃO (1)
}

\author{
GIOVANI OLEGÁRIO DA SILVA $\left(2^{*}\right)$; ARIONE DA SILVA PEREIRA $\left({ }^{3}\right)$; \\ VELCI QUEIROZ DE SOUZA $\left({ }^{4}\right)$; FERNANDO IRAJÁ FÉLIX DE CARVALHO $\left({ }^{4}\right)$; \\ ANTÔNIO COSTA DE OLIVEIRA $\left({ }^{4}\right)$; IVANDRO BERTAN $\left({ }^{4}\right)$; ROBERTO FRITSCHE NETO $\left({ }^{5}\right)$
}

\begin{abstract}
RESUMO
O trabalho teve por objetivo verificar as implicações da utilização da análise de importância de caracteres na eliminação de caracteres avaliados para o cálculo da distância genética de progênies de batata (Solanum tuberosum L.) nas primeiras gerações de seleção. Os experimentos foram desenvolvidos em casa plástica (geração de seedlings) e em campo (primeira geração clonal), na Embrapa Clima Temperado, Pelotas, Estado do Rio Grande do Sul em outono de 2004 e outono de 2005. O estudo demonstrou que a análise de importância de caracteres foi eficiente para diminuir o número de caracteres necessários à classificação das progênies de batata em relação à dissimilaridade. O formato de tubérculo foi o caráter com maior eficiência para o estudo de dissimilaridade em progênies de batata.
\end{abstract}

Palavras-chave: Solanum tuberosum L., contribuição relativa de caracteres.

\section{ABSTRACT \\ IMPORTANCE OF CHARACTERS IN THE DISSIMILARITY OF POTATO PROGENNIES IN EARLY GENERATIONS}

The objective of the present work was to access the implications of the use of analysis of importance of characters in the elimination of appraised characters for calculating genetic distance of potato (Solanum tuberosum L.) progenies in early generations. The experiments were carried out in plastic house (seedling generation) and in the field (first clonal generations) at Embrapa Temperate Climate, Pelotas, Rio Grande do Sul State in autumn 2004 and 2005. The study was demonstrated the efficiency of the analysis in importance of characters for reducing the number of characters necessary for classifying potato progenies in relation to the dissimilarity. Tuber shape was the character with the largest efficiency for the dissimilarity study in potato progenies.

Key words: Solanum tuberosum L., relative contribution of characters.

(1) Recebido para publicação em 7 de dezembro de 2005 e aceito em 12 de julho de 2007.

( ${ }^{2}$ ) Embrapa Hortaliças, BR 060, Caixa Postal 218, 70359-970 Gama (DF). E-mail: olegario@cnph.embrapa.br $\left({ }^{*}\right.$ ) Autor correspondente.

$\left({ }^{3}\right)$ Embrapa Clima Temperado, Caixa Postal 403, 96001-970 Pelotas (RS). E-mail: arione@cpact.embrapa.br.

$\left({ }^{4}\right)$ Universidade Federal de Pelotas (UFPel), Campus Universitário, Caixa Postal 354, 96010-900 Pelotas (RS). E-mail: velciq@gmail.com, carvalho@ufpel.edu.br, acostol@terra.com.br, bertan.ivandro@gmail.com

$\left({ }^{5}\right)$ Escola Superior de Agricultura Luiz de Queiroz, ESALQ/USP, Caixa Postal 9, 13418-900 Piracicaba (SP). E-mail: rfneto@hotmail.com 


\section{Introdução}

Os estudos de distância genética têm sido de grande importância em programas de melhoramento, por fornecerem informações sobre parâmetros de identificação de genitores que possibilitem grande efeito heterótico na progênie e maior probabilidade de recuperar genótipos superiores nas progênies. Os métodos de agrupamento têm por finalidade separar um grupo original de observações, a partir da matriz de similaridade ou dissimilaridade, em vários subgrupos, de forma que se obtenha homogeneidade dentro e heterogeneidade entre os subgrupos, possibilitando a visualização do comportamento de um genótipo em relação aos demais, de acordo com a distância genética indicada nas matrizes (CRUZ E RegazZI, 2001).

Pela análise da importância de caracteres de SINGH (1981), é possível classificar as variáveis estudadas de acordo com sua contribuição para a divergência genética total e eliminar aquelas com menor contribuição.

Estudando as gerações de seedlings, primeira e segunda geração clonal, Gopal (2001) verificou pouca contribuição dos caracteres uniformidade de formato e uniformidade de tamanho para a variação populacional.

O objetivo deste trabalho foi verificar as implicações da utilização da análise de importância de caracteres na eliminação de caracteres avaliados para o cálculo da distância genética de progênies de batata em gerações precoces.

\section{Material e Métodos}

Os experimentos foram realizados no campo experimental da Embrapa Clima Temperado, Pelotas, Estado do Rio Grande do Sul. Foi avaliada uma população híbrida de batata obtida de 15 cruzamentos contrastantes para os caracteres estudados. No outono de 2004, as sementes foram germinadas em sementeiras e os seedlings transplantados para sacos plásticos em casa plástica para produção de minitubérculos. O delineamento experimental foi realizado em blocos ao acaso e três repetições. Cada parcela constituiu-se de 20 seedlings de uma família (cruzamento), efetuando-se a colheita e as avaliações dos tubérculos após 77 dias.

Os tubérculos foram armazenados a $4^{\circ} \mathrm{C}$ até o outono de 2005, quando um tubérculo de cada planta foi plantado no campo, utilizando o mesmo delineamento do experimento anterior. Após a maturação, as plantas foram colhidas separadamente e realizadas as avaliações nos tubérculos.
Os caracteres avaliados nos tubérculos de cada planta foram: (1) rendimento de tubérculos ( $\mathrm{g}$ planta $\left.^{-1}\right)$; (2) número de tubérculos por planta; (3) massa média de tubérculos (g); (4) formato de tubérculo; (5) uniformidade de formato de tubérculo; (6) tamanho do maior tubérculo; (7) uniformidade de tamanho de tubérculo; (8) aspereza da película; (9) profundidade dos olhos; (10) sobrancelha; (11) achatamento de tubérculos; (12) curvatura de tubérculo; (13) apontamento de tubérculos e (14) aparência de tubérculo. Os onze últimos caracteres foram avaliados utilizando escalas de notas de cinco pontos.

Os dados foram submetidos à análise de variância em cada experimento e conjuntamente, com efeito fixo para ambiente e aleatório para genótipos; e a análise da distância generalizada de Mahalanobis $\left(D^{2}\right)$, com a utilização do programa GENES (CRUZ, 2001), sendo a matriz de dissimilaridade transferida para o programa NTSYSpc (RoHLF, 2000) para efetuar o agrupamento em dendrograma pelo método de agrupamento das distâncias médias (UPGMA) e diagnóstico das correlações co-fenéticas entre as matrizes e os agrupamentos (ROHLF E SOKAL, 1981). A importância relativa dos caracteres, foi estimada por meio da participação dos componentes de $\mathrm{D}^{2}$, relativos a cada característica, no total da dissimilaridade observada (SINGH, 1981).

Para verificar o efeito da eliminação de caracteres com menor contribuição à divergência entre as progênies, optou-se por descartar seis caracteres que menos contribuíram para a divergência, e que também não foram significativos a cada período de cultivo e realizado novo cálculo de dissimilaridade para as comparações. Os caracteres eliminados para geração de seedlings foram os seguintes: profundidade de olho, massa média de tubérculos, uniformidade de tamanho, achatamento, aspereza e uniformidade de formato de tubérculo. Para a primeira geração clonal, foram eliminados: tamanho, achatamento, uniformidade de formato, aparência, rendimento e uniformidade de tamanho de tubérculo.

Para melhor quantificação do efeito das eliminações de caracteres, foram calculadas correlações entre as matrizes de dissimilaridade, com sua significância testada pela estatística de Mantel (1967).

\section{Resultados e Discussão}

A análise de variância dos dados da geração de seedlings atestou que os caracteres uniformidade de formato e de tamanho de tubérculo não foram significativos em diferenciar os genótipos avaliados. 
Da mesma forma que para a geração de seedlings, os caracteres uniformidade de formato e de tamanho de tubérculo, além de aparência, tamanho e achatamento de tubérculo não foram significativos em diferenciar os genótipos avaliados na primeira geração de campo. Os coeficientes de variação que são indicativos da precisão experimental, em geral foram maiores na primeira geração de campo, revelando ser o ambiente o que influenciou mais na manifestação dos caracteres nesta geração. No entanto, para a maioria dos caracteres em ambas as gerações, os coeficientes de variação foram reduzidos; com exceção para achatamento de tubérculo para as duas gerações (38,87 e 36,85 para a geração de seedlings e primeira geração de campo respectivamente) e para número e rendimento de tubérculos para a primeira geração de campo $(32,53$ e 25,62 respectivamente), que demonstraram ser caracteres com forte influência ambiental nas respectivas condições de cultivo.

Tabela 1. Contribuição relativa dos parâmetros para divergência de progênies de batata, pela distância generalizada de Mahalanobis, na geração de seedlings e na primeira geração de campo. Pelotas, 2005

\begin{tabular}{|c|c|c|c|c|}
\hline Caráter & S. j. & Valor & S. j. & Valor \\
\hline & & $\%$ & & $\%$ \\
\hline Formato & 2347,23 & 17,51 & 1762,64 & 26,10 \\
\hline Curvatura & 2330,89 & 13,42 & 1226,90 & 19,21 \\
\hline Apontamento & 2147,22 & 11,36 & 1095,98 & 17,01 \\
\hline Rendimento & 1870,98 & 10,77 & 915,81 & 13,36 \\
\hline Aparência & 1664,99 & 10,58 & 725,16 & 7,62 \\
\hline $\begin{array}{l}\text { Número } \\
\text { de tubérculos }\end{array}$ & 882,87 & 8,16 & 707,37 & 6,46 \\
\hline Sobrancelha & 628,62 & 7,72 & 307,96 & 2,81 \\
\hline Tamanho & 586,88 & 5,37 & 169,36 & 2,14 \\
\hline $\begin{array}{l}\text { Uniformidade } \\
\text { de formato }\end{array}$ & 569,45 & 3,27 & 140,92 & 1,28 \\
\hline Aspereza & 553,22 & 2,99 & 129,32 & 1,18 \\
\hline Achatamento & 479,74 & 2,76 & 110,66 & 1,01 \\
\hline $\begin{array}{l}\text { Uniformidade } \\
\text { de tamanho }\end{array}$ & 252,16 & 2,45 & 110,17 & 1,00 \\
\hline $\begin{array}{l}\text { Massa média } \\
\text { de tubérculos }\end{array}$ & 237,80 & 2,36 & 68,43 & 0,62 \\
\hline $\begin{array}{l}\text { Profundidade } \\
\text { de olho }\end{array}$ & 17,76 & 1,28 & 14,77 & 0,13 \\
\hline
\end{tabular}

S. J.: valor estimado da estatística de SINGH (1981).

Desconsiderando os caracteres uniformidade de formato e de tamanho que não foram significativos na análise de variância conjunta, a maioria dos caracteres (dois terços) apresentou interação genótipo $x$ ambiente significativa, indicando que as inferências devem ser efetuadas em separado para cada ambiente. Comparando-se os caracteres excluídos, verificou-se que em ambas as gerações foram excluídos uniformidade de formato e de tamanho de tubérculo os únicos que não apresentaram diferenças significativas para efeito de genótipos na análise conjunta, e achatamento de tubérculo. Apesar de ter havido significância na geração de seedlings, contribuíram com pequena proporção para a dissimilaridade (Tabela 1), corroborando com GopaL (2001) que verificou pouca contribuição dos caracteres uniformidade de formato e uniformidade de tamanho para a variação populacional na geração de seedlings, assim como na primeira e na segunda gerações clonais.

No caráter formato de tubérculo verificou-se a maior contribuição para a divergência em ambas as gerações. No entanto, por haver interação genótipo $x$ ambiente significativa, não classificou igualmente todas as progênies nas duas gerações.

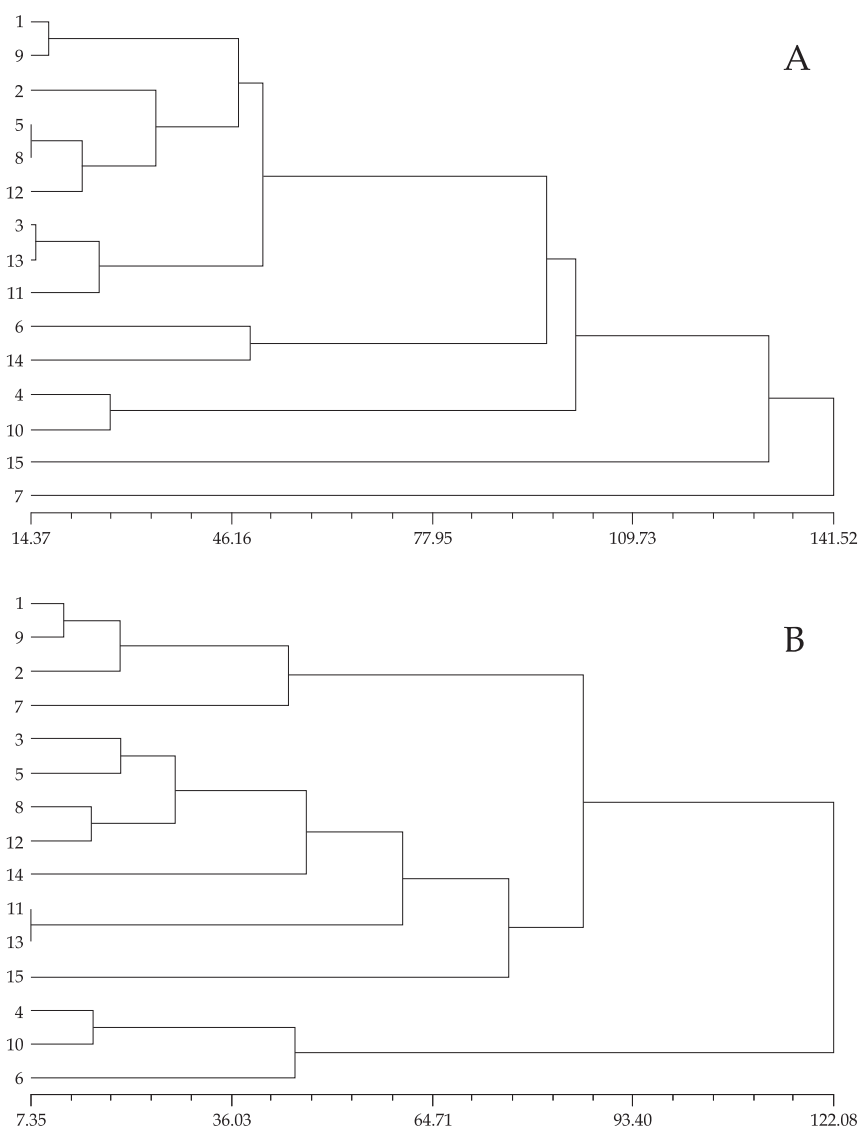

Figura 1. Dendrogramas de 15 progênies de batata na geração de seedlings, pelo método de agrupamento UPGMA da distância genética de Mahalanobis; A: com 14 caracteres fenotípicos, e coeficiente de correlação cofenética (r) de 0,79; B: com 9 caracteres fenotípicos, coeficiente de correlação cofenética (r) de 0,80. Pelotas, 2005. 
Comparando-se os dendrogramas, com e sem a retirada das variáveis na geração de seedlings (Figura 1) e na primeira geração de campo (Figura 2), verificase que em algumas situações os genótipos não estiveram agrupados da mesma forma nas duas situações (com e sem retirada de caracteres). No entanto, de maneira geral uma similaridade muito grande entre os agrupamentos nas situações com e sem retirada de caracteres pode ser notada para ambas as gerações (Figuras 1 e 2). Uma maneira de tornar esta comparação menos subjetiva foi a de comparar as matrizes pelo cálculo da correlação (MANTEL, 1967). Os valores de correlação entre as duas matrizes para a geração de seedlings (Figura 1) e primeira geração de campo (Figura 2) foram de 0,85 e 0,93, altamente significativas pelo teste de Mantel, (1967), demonstrando que a retirada dos caracteres não acarretou grandes modificações entre as progênies em relação à dissimilaridade entre elas.
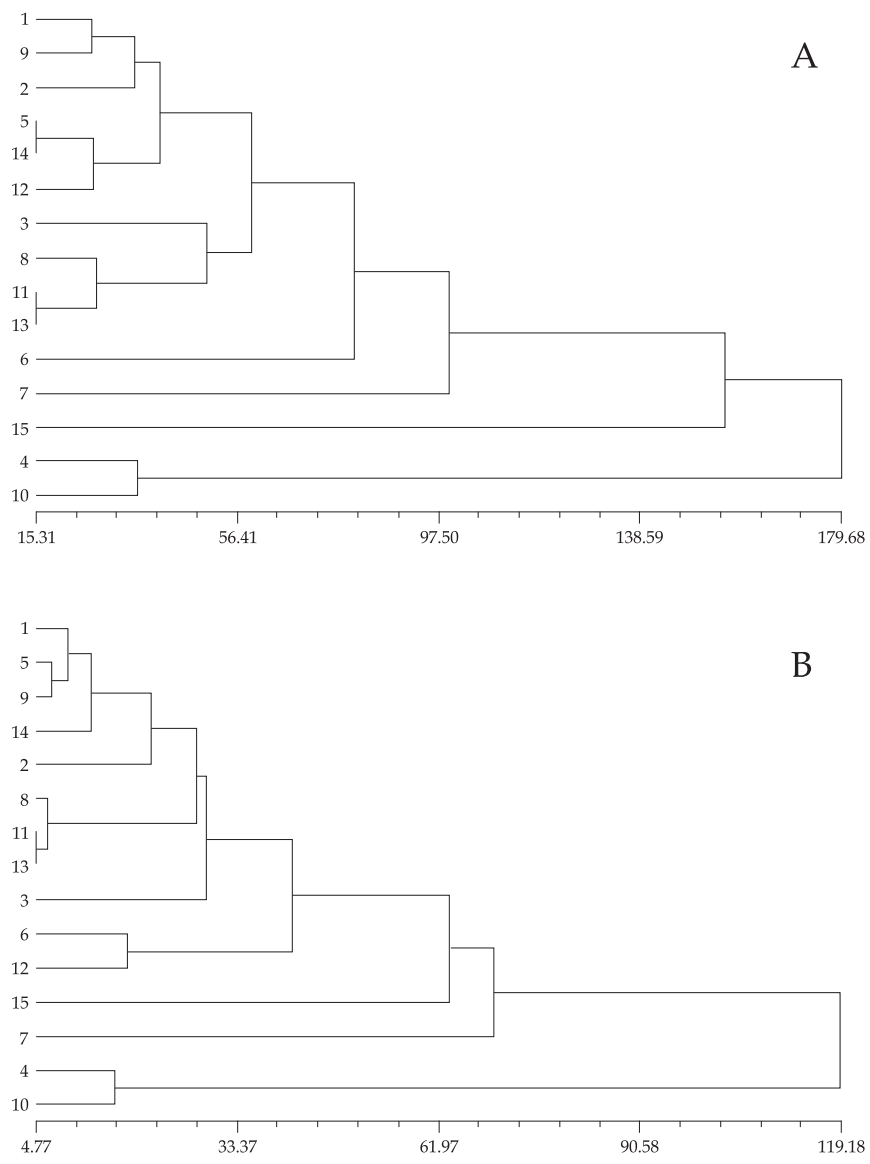

Figura 2. Dendrogramas de 15 progênies de batata em primeira geração clonal, pelo método de agrupamento UPGMA da distância genética de Mahalanobis. A: com 14 caracteres e coeficiente de correlação cofenética (r) de 0,78 . B: com 9 caracteres fenotípicos e coeficiente de correlação cofenética (r) de 0,82. Pelotas, 2005.

\section{Conclusões}

1. A análise de importância de caracteres é eficiente para a diminuição do número de caracteres necessários à classificação das progênies de batata em relação à dissimilaridade.

2. O formato de tubérculo é o caráter com maior eficiência para estudar dissimilaridade em progênies de batata.

\section{Referências}

CRUZ, C.D. Programa Genes: Aplicativo computacional em genética e estatística. Viçosa; Editora UFV, 2001. 648p.

CRUZ, C.D.; REGAZZI, A.J. Métodos biométricos aplicados ao melhoramento genético. Viçosa; UFV: Imprensa Universitária, 2001. 390p.

GOPAL, J. Genetic parameters and character associations for family selection in potato breeding programmes. Journal of Genetics e Breeding, Roma, v. 55, p. 201-208, 2001.

MANTEL, N. The detection of disease clustering and a generalized regression approach. Cancer Research, Chestnut, v.27, n.2, p.209-220, 1967.

ROHLF, F.J. 2000. NTSYSpc numerical taxonomy and multivariate analysis system version 2.1. Exeter Software, Setauket, NY.

ROHLF, F. J.; SOKAL, R.R. N. Comparing numerical taxonomic studies. Systematic Zoology. v. 30, p.459-499, 1981.

SINGH, D. The relative importance of characters affecting genetic divergence. The Indian Journal of Genetics e Plant Breeding, New Delhi, v.41, p.237-245, 1981. 